\title{
Automatic Welding System of Aluminum Pipe by Monitoring Backside Image of Molten Pool Using Vision Sensor*
}

\author{
Ario Sunar BASKORO**, Masashi KABUTOMORI** and Yasuo SUGA*** \\ ${ }^{* *}$ Graduate School of Science and Technology, Keio University \\ 3-14-1 Hiyoshi, Kohoku-ku, Yokohama 223-8522, Japan \\ E-mail: ario@suga.mech.keio.ac.jp \\ *** Faculty of Science and Engineering, Keio University \\ 3-14-1 Hiyoshi, Kohoku-ku, Yokohama 223-8522, Japan \\ E-mail: suga@mech.keio.ac.jp
}

\begin{abstract}
An automatic welding system using Tungsten Inert Gas (TIG) welding with vision sensor for welding of aluminum pipe was constructed. This research studies the intelligent welding process of aluminum alloy pipe 6063S-T5 in fixed position and moving welding torch with the $\mathrm{AC}$ welding machine. The monitoring system consists of a vision sensor using a charge-coupled device (CCD) camera to monitor backside image of molten pool. The captured image was processed to recognize the edge of molten pool by image processing algorithm. Neural network model for welding speed control were constructed to perform the process automatically. From the experimental results it shows the effectiveness of the control system confirmed by good detection of molten pool and sound weld of experimental result.
\end{abstract}

Key words: Aluminum Pipe, Backside Image of Molten Pool, Vision Sensor, Welding Speed Control, Image Processing, Neural Network

\section{Introduction}

Recently, arc welding process of aluminum alloys is very important in the automotive and maritime sectors, and has potential for high strength aerospace alloys due to lighter and cheaper structures. However, comparing to plate welding, welding of aluminum pipe is more difficult due to the characteristics of the welding process and aluminum properties. If the constant welding conditions are maintained over the full joint length, the bead width becomes wider as the circumferential welding of small diameter pipes progresses. Therefore, the control of bead width products has been very difficult to perform by constant welding conditions. The automation of bead width control requires the ability to adjust speed of welding torch or control welding arc current.

There have been many studies on welding process of aluminum pipe by rotating the pipe and welding torch was kept static ${ }^{[1]-[4]}$. Unfortunately, the welding process was conducted in rotated pipe. Having welded pipe in fixed position, obviously, the excessive arc current yields burn through of metals; in contrary, insufficient arc current produces imperfect welding. In order to avoid these errors and to obtain the uniform weld bead over the entire circumference of the pipe, the welding conditions should be controlled as the welding proceeds, so that the system must be intelligent. For that purpose, this paper proposes welding penetration control of fixed aluminum alloy pipe A6063S-T5 using vision sensor. In this experiment, AC welding machine with square-wave current was used.

The previous research ${ }^{[5]}$ was successfully conducted to weld stainless steel pipe, with

*Received 27 June, 2007 (No. 07-0273) [DOI: 10.1299/jmmp.2.582] 
the diameter of pipe was $42.7 \mathrm{~mm}$ and $2 \mathrm{~mm}$ in thickness. However, this research was conducted for welding aluminum material with smaller size of $37.8 \mathrm{~mm}$ in diameter and 2 $\mathrm{mm}$ in thickness. Compared with the detected stainless steel's image, image of aluminum molten pool has very low brightness. Therefore, new technique in detecting molten pool edge was proposed in this paper. In order to show the validity of the image processing algorithm, the results of detected image of molten pool and measured back bead data were compared. Several experiments without control were conducted to provide the training data for control system. In this study, neural network model was utilized to control the welding penetration by modifying speed as welding parameter.

\section{Experiment System}

The experimental device, which was used in this experiment, is shown in Fig. 1. The overall system used the circumferential welding system, CCD camera and the image digitizer $(256 \times 220$ pixels, 8bit), the personal computer (CPU: $1.2 \mathrm{MHz})$, two stepping motors which are used for the revolution and longitudinal movement of the welding torch, the small-sized stepping motor which was used for arc length control, arc current measurement equipment, the gearbox, and the TIG welding machine.

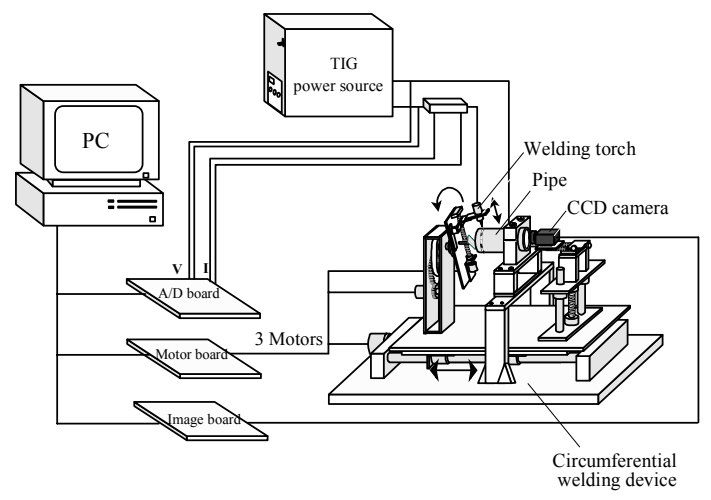

Fig. 1 Schematic of experimental device

A CCD camera was used for monitoring of molten pool and sent the image data to personal computer through the image digitizer. Time required for capturing a single frame was $1 / 30$ s. The backside image of molten pool was processed in the personal computer to detect the image parameter of molten pool. Base metal used in this experiment was aluminum alloy pipe A6063S-T5. Pulsed TIG AC welding machine with square-wave current and pure argon shielding gas was used. To obtain good image of molten pool, the back shield gas with pure argon was utilized. The method of the study was conducted using several experimental works, which are: image processing algorithm construction to recognize the molten pool, welding process without control for determining welding and image parameters to train the neural network system, and finally conducting the experiment with control using neural network control system.

\section{Monitoring of Molten Pool}

In this section, the image processing algorithm to recognize the molten pool image and result of preliminary experiment using image processing algorithm are described.

\subsection{Image Processing Algorithm}

In order to capture the backside molten pool image, CCD camera was used for acquisition of reflected image from the mirror. The arrangement of mirror and camera is shown in Fig. 2(a). The mirror with the size of $29 \times 20 \mathrm{~mm}$ was set with $60^{\circ}$ about the horizontal axes. The mirror rotates along the welding torch during the pipe welding process 
and reflects the image into the CCD camera. The example result of backside image of molten pool is shown in Fig. 2(b).

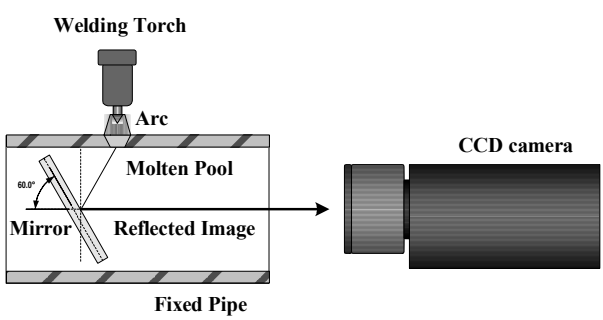

(a) Schematic of monitoring

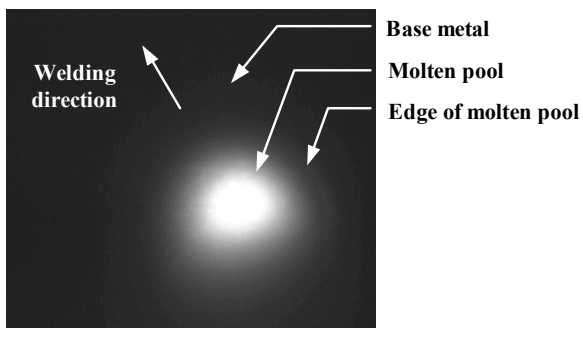

(b) Backside image of molten pool

Fig. 2 Monitoring system of backside image of molten pool

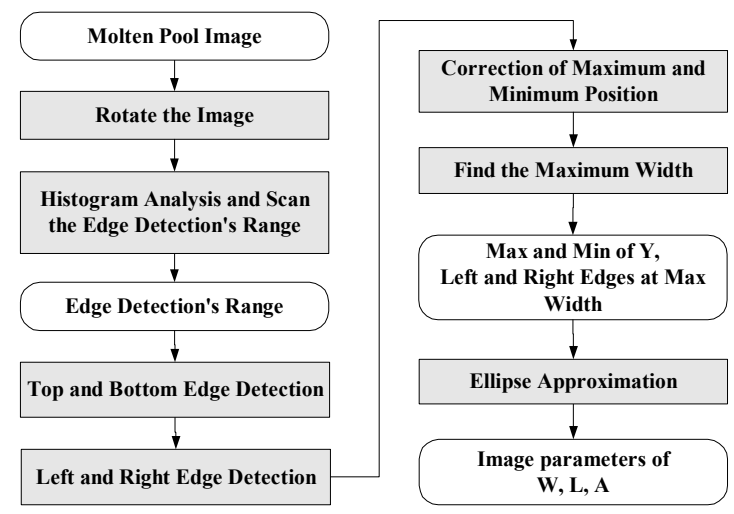

Fig. 3 Flowchart of image processing algorithm

Figure 3 presents the flowchart of image processing algorithm. According to the low brightness of aluminum's molten pool due to the low melting point, the stable and robust image processing algorithm must be constructed. Applying ellipse approximation (top and bottom ellipse) as an improvement of previous algorithm (only top ellipse) ${ }^{[6]}$, this process produced the improved image parameters of width (W), length (L) and area (A). The detail of image processing algorithm will be discussed as follows.

(1) Rotation of image: The first process of the recognition was to rotate the original image into uniform position as shown in Fig. 4(a), (b), and (c). After reading the image, the histogram process was conducted. With threshold value produced from minimum scan of histogram frequency, the binarization was conducted as shown in Fig. 4(b). In order to eliminate noises, the pick noise process was performed. Then the center of gravity of the bright area was obtained from the binary image. The image was aligned by rotating the center of gravity to the center of image to produce the image as shown in Fig. 4(c).

(2) Histogram analysis and scan the edge detection's range: From the histogram analysis, the frequency of brightness value of the image was obtained. The brightness average, $g_{\text {avg }}$ and accumulation of the percentage of brightness average, $p_{\text {avg }}$ were obtained by the Eqs. (1) and (2), respectively.

$$
\begin{aligned}
& g_{\text {avg }}= \frac{\sum_{i=0}^{i=255}(f(i) \times i)}{\sum_{i=0}^{i=255} i} \\
& p_{\text {avg }}=\frac{\sum_{i=0}^{i=a v g} f(i)}{\sum_{i=0}^{i=255} f(i)} \times 100 \%
\end{aligned}
$$

where $f(i)$ is the frequency of brightness at i. 


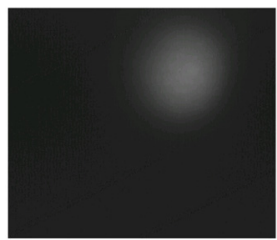

(a) Original Image

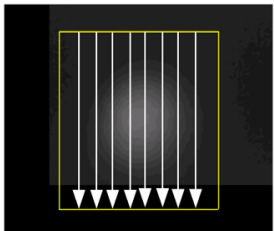

(d) Vertical Scanning

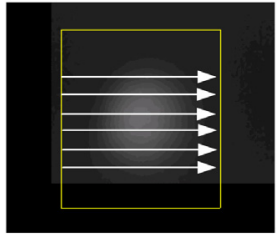

(g) Horizontal Scanning

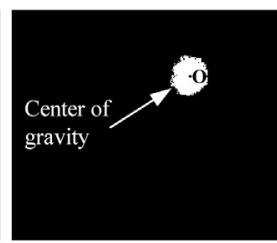

(b) Binary Image

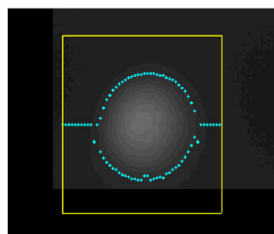

(e) Top and Bottom

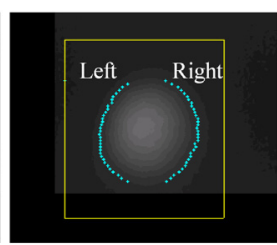

(h) Left and Right Edges

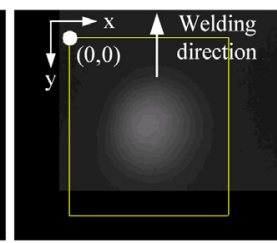

(c) Rotated Image

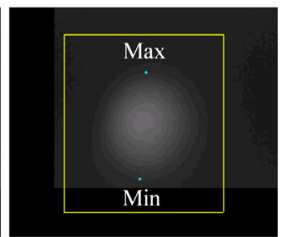

(f) Maximum and Minimum Position

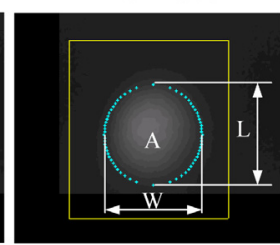

(i) Ellipse Approximation

Fig. 4 Results of image processing.

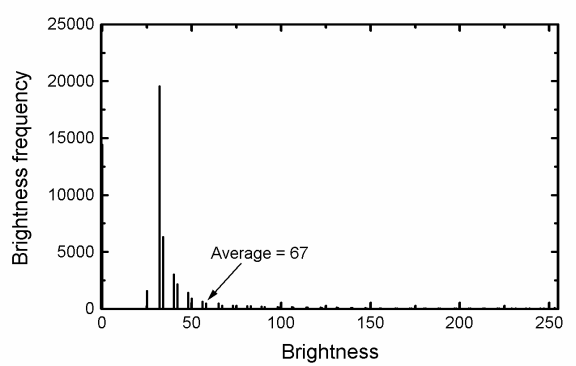

(a) Brightness frequency of molten pool image

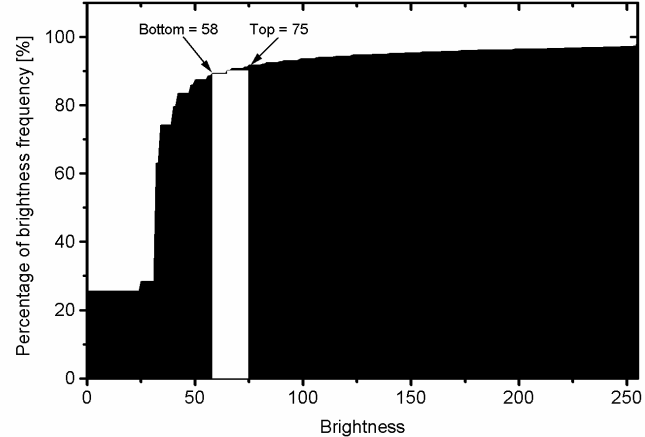

(b) Percentage of brightness frequency to find top and bottom brightness of edge detection

Fig. 5 Method to find top and bottom brightness of edge detection

Table 1 Rules of top and bottom brightness of edge detection

\begin{tabular}{|c|c|c|c|c|}
\hline $\begin{array}{l}\text { Brightness } \\
\text { Average } \\
\left(g_{\text {avg }}\right)\end{array}$ & $\begin{array}{c}\text { Percentage at } \\
\text { Brightness } \\
\text { Average } \\
\left(\mathrm{p}_{\mathrm{avg}}\right)\end{array}$ & $\begin{array}{c}\text { Histogram } \\
\text { Frequency at } \\
\text { Brightness of } 255 \\
(\mathrm{f}(255))\end{array}$ & $\begin{array}{c}\text { Percentage of } \\
\text { Top Brightness } \\
\left(\mathrm{p}_{\text {top }}\right)\end{array}$ & $\begin{array}{c}\text { Percentage of } \\
\text { Bottom Brightness } \\
\left(\mathrm{p}_{\mathrm{btm}}\right)\end{array}$ \\
\hline$<35$ & All values & $<1000$ & $\mathrm{p}_{\text {top }}=\mathrm{p}_{\text {avg }}+2.0 \%$ & $\mathrm{p}_{\mathrm{btm}}=\mathrm{p}_{\mathrm{avg}}+1.0 \%$ \\
\hline$>35$ and $<48$ & $<90.0 \%$ & $<1000$ & $\mathrm{p}_{\mathrm{top}}=\mathrm{p}_{\mathrm{avg}}+1.0 \%$ & $\mathrm{p}_{\mathrm{btm}}=\mathrm{p}_{\mathrm{avg}}-1.0 \%$ \\
\hline$>35$ and $<48$ & $>90.0 \%$ & $<1000$ & $\mathrm{p}_{\mathrm{top}}=\mathrm{p}_{\mathrm{avg}}+0.5 \%$ & $\mathrm{p}_{\mathrm{btm}}=\mathrm{p}_{\mathrm{avg}}-0.5 \%$ \\
\hline$>48$ and $<70$ & $<90.0 \%$ & $>1000$ & $\mathrm{p}_{\mathrm{top}}=\mathrm{p}_{\mathrm{avg}}+2.0 \%$ & $\mathrm{p}_{\mathrm{btm}}=\mathrm{p}_{\mathrm{avg}}-2.0 \%$ \\
\hline$>48$ and $<70$ & $>90.0 \%$ & $>1000$ & $\mathrm{p}_{\mathrm{top}}=\mathrm{p}_{\mathrm{avg}}+1.0 \%$ & $\mathrm{p}_{\mathrm{btm}}=\mathrm{p}_{\mathrm{avg}}-1.0 \%$ \\
\hline$>70$ & All values & $>1000$ & $\mathrm{p}_{\mathrm{top}}=\mathrm{p}_{\mathrm{avg}}+0.5 \%$ & $\mathrm{p}_{\mathrm{btm}}=\mathrm{p}_{\mathrm{avg}}-0.5 \%$ \\
\hline
\end{tabular}

By evaluating the frequency of brightness at 255, brightness average, $\mathrm{g}_{\text {avg }}$ and percentage at brightness average, $\mathrm{p}_{\mathrm{avg}}$, the range of threshold value could be determined. Several rules that have been determined from the observation and experience were applied to obtain the percentage of top threshold, $\mathrm{p}_{\text {top }}$ and bottom threshold, $\mathrm{p}_{\mathrm{btm}}$ as shown in Table 1. Then the value of brightness at that percentage could be determined. Figure 5 shows the example of method to find top and bottom brightness of edge detection. With the brightness 
average of 67 in Fig. 5(a) and applying the rules in Table 1, top brightness of 75 and bottom brightness of 56 could be determined as shown in Fig. 5(b). This process improved the previous process $^{[6]}$ that used contrast enhancement.

(3) Maximum and Minimum Position: The differential values of brightness along vertical axis $g_{v}{ }^{\prime}(i, j)$ were obtained with the following formula.

$g_{v}{ }^{\prime}(i, j)=g(i, j+1)-g(i, j)$

where $g(i, j)$ is the brightness value of a pixel at $(i, j)$

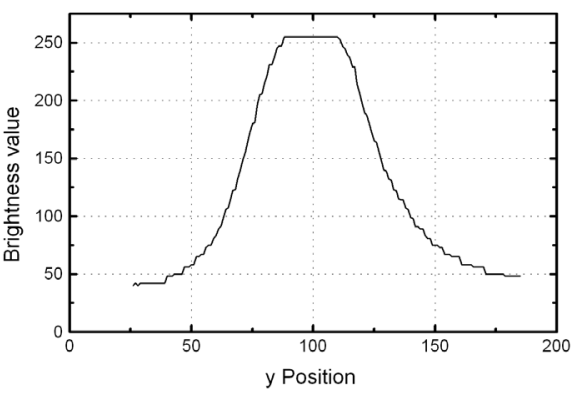

(a) Brightness distribution at $\mathrm{x}=136$

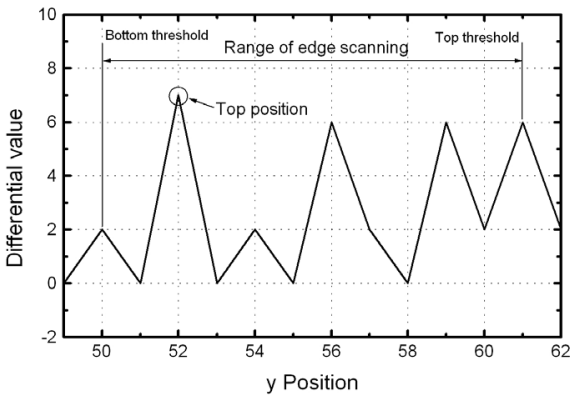

(c) Determination of top position

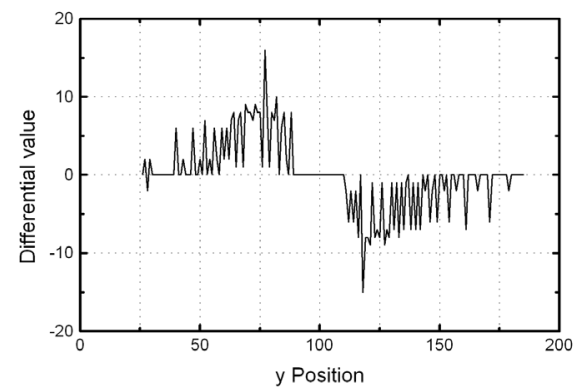

(b) Differential value of brightness distribution at $\mathrm{x}=136$

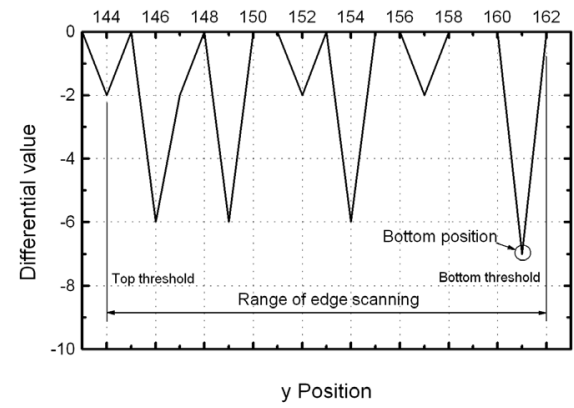

(d). Determination of bottom position

Fig. 6 Example of detection of top and bottom position of molten pool's edge

Because the position of top and bottom position was very difficult to be decided from differential value of brightness distribution, the top and bottom threshold values were utilized as range of edge scanning. Figure 6 shows the example of detection of top and bottom position of molten pool's edge. In Fig. 6(a) and (b) the brightness distribution at $\mathrm{x}=$ 136 and differential value of brightness distribution was shown, respectively. The top position was detected from the edge detection's range with the biggest value of differential value as shown in Fig. 6(c). In contrary, the bottom position was detected as the smallest value of differential value as shown in Fig. 6(d). The process was repeated along $x$ position inside the set window as shown in Fig. 4(d). Finally, by comparing the highest and lowest position of top and bottom as shown in Fig. 4(e), we could find the maximum position $y_{\text {top }}$ and minimum position $\mathrm{y}_{\mathrm{btm}}$ as shown in Fig. 4(f).

(4) Left and Right Edges: The process to detect left and right edges was same as the process to find maximum and minimum position described at previous section. The differential values of brightness along horizontal axis $g_{h}{ }^{\prime}(i, j)$ were obtained, with the formula below.

$$
g_{h}{ }^{\prime}(i, j)=g(i+1, j)-g(i, j)
$$

By applying the top threshold and bottom threshold as the edge detection's range, the left and right edges were detected. This process was repeated along the y position inside the set window from the maximum position until the minimum position as shown in Fig. 4(g). 
Finally, all of the left and right edges were detected as shown in Fig. 4(h).

(5) Error Correction: Detected edges from previous process may have the error possibility due to reflection image that is usually occurs at above of $350^{\circ}$, so that the error correction must be performed. The detected error occurred below the $\mathrm{y}_{\text {top }}$ and above $\mathrm{y}_{\mathrm{btm}}$ for some certain range. With the error filtering process, the new $y_{\text {top }}$ and $y_{b t m}$ were obtained.

(6) Maximum Width Detection: In order to find the maximum width, the scanning of widest value of left and right edges below $y_{\text {top }}$ was conducted. At the maximum width, the left edge $\mathrm{L}_{\text {lmax }}$ and right edge $\mathrm{L}_{\mathrm{rmax}}$ were determined. These points were used for the building of ellipse approximation.

(7) Ellipse Approximation: The detected edges were not used directly to get the image parameters of molten pool. The more robust image processing algorithm by ellipse approximation was constructed to avoid the error possibilities and unsteady of detected edge. The inputs to build the ellipse approximation were: (1) Maximum position, $\mathrm{y}_{\text {top }}$, (2) Minimum position, $\mathrm{y}_{\mathrm{btm}}$, (3) Left edge at maximum width, $\mathrm{L}_{\mathrm{lmax}}$, and (4) Right edge at maximum width, $\mathrm{L}_{\mathrm{rmax}}$. With the construction of ellipse along the detected edge, it overcame the lack of detected edges. The result of ellipse approximation is shown in Fig. 4(i).

\subsection{Results of Image Processing Algorithm}

In order to show the validity of the proposed image processing algorithm, the algorithm was applied to the current system. Figure 7 shows the result of preliminary experiment without control to examine the image processing algorithm. Result of detected edge is shown in Fig. 7(a). The relation between measured back bead width and detected molten pool width are shown in Fig. 7(b). Image resolution is $0.06 \mathrm{~mm} /$ pixel. It is clearly seen that that image processing algorithm could detect the molten pool width with good approximation. However, some errors still occur during the monitoring process with the average errors of $0.33 \mathrm{~mm}$.

The cause of the errors might come from the detected threshold values as the brightness range for scanning the edge of molten pool. The judgment of rules to obtain top and bottom brightness of edge detection could provide error in judgment of edge detection. Very low brightness of molten pool due to higher welding speed also generated poor detection of threshold values; therefore the edge detection could be failed.

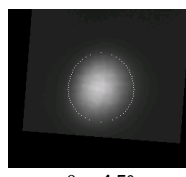

$\theta=4.5^{\circ}$

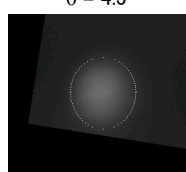

$\theta=99^{\circ}$

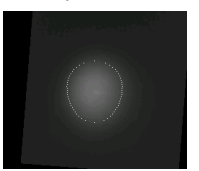

$\theta=184.5^{\circ}$

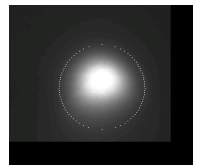

$\theta=270^{\circ}$

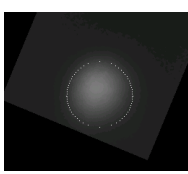

$\theta=22.5^{\circ}$

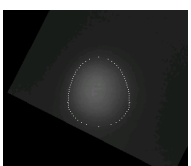

$\theta=117$

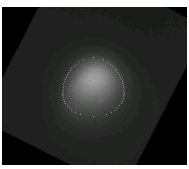

$\theta=207^{\circ}$

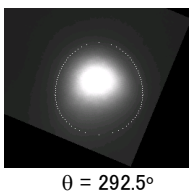

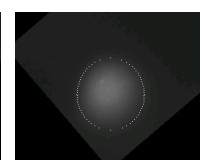

$\theta=49.5^{\circ}$

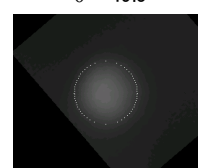

$\theta=139.5^{\circ}$

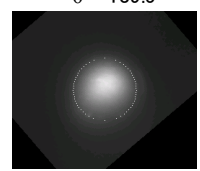

$\theta=229.5^{\circ}$

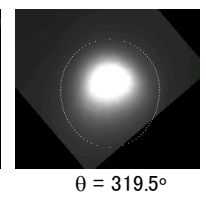

$\theta=319.5^{\circ}$

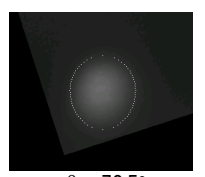

$\theta=72.5^{\circ}$

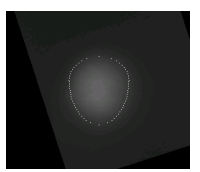

$\theta=171^{\circ}$
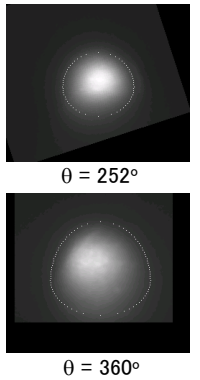

(a) Results of edge detection 


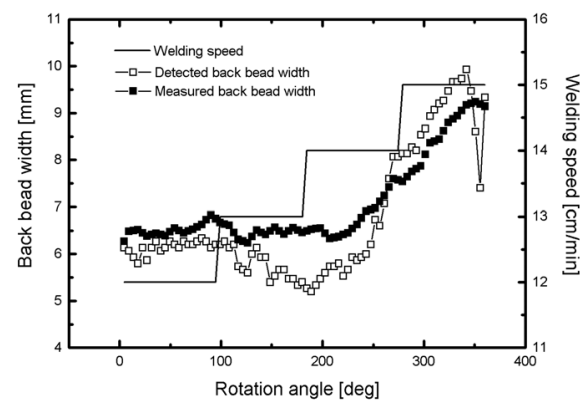

(b) Comparison between detected and measured back bead width

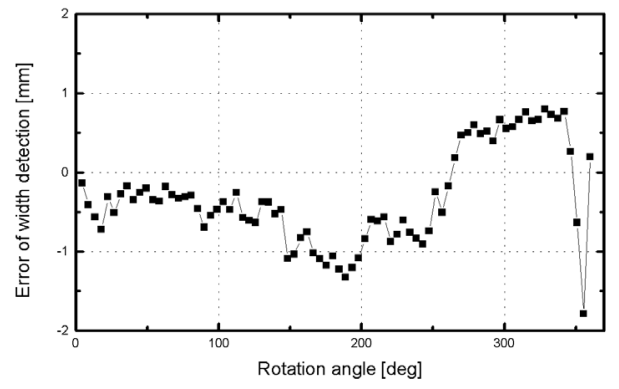

(c) Error of detected back bead width

Fig. 7 Result of preliminary experiment

At the end of the rotation, some errors might occur due to reflection from the surface of welded back bead to the molten pool image. Another reason of this error came from the error of the measurement of back bead width. Although the image processing algorithm had some errors, the algorithm with ellipse approximation was considered as the good approach. It could be assured that the ellipse approximation detected edge of molten pool robustly. Compared with previous research ${ }^{[6]}$, this image processing algorithm has improved the detection.

\section{Experiment}

Experiments were conducted in two ways: experiment without control to collect training data and experiment with control using neural network control system.

\subsection{Experiment Without Control}

The material properties and welding conditions of this study is shown in Table 2 . Welding experiments were conducted in TIG welding to find the training data by welding the pipe with several different welding speeds. The welding speed of $12-20 \mathrm{~cm} / \mathrm{min}$ was implemented at four range of rotation angle, which notated as shown in Table 3.

Table 2 Material properties and welding conditions

\begin{tabular}{cc} 
Table 2 Material properties and welding conditions \\
\hline Base metal & Al-6063S-T5 \\
Diameter of pipe $(\mathrm{mm})$ & 37.8 \\
Thickness of pipe $(\mathrm{mm})$ & 2.0 \\
Density $\left(\mathrm{g} / \mathrm{cm}^{3}\right)$ & 2.69 \\
Melting point $\left({ }^{\circ} \mathrm{C}\right)$ & $615-655$ \\
Thermal conductivity $\left(\mathrm{W} / \mathrm{m} . \mathrm{K}\right.$ at $\left.25^{\circ} \mathrm{C}\right)$ & 209 \\
Welding machine & $\mathrm{AC}$ \\
Electrode & $2 \% \mathrm{Th}-\mathrm{W}(\varnothing 2.4 \mathrm{~mm})$ \\
Nominal arc length $(\mathrm{mm})$ & 1.5 \\
Welding current, I $(\mathrm{A})$ & $50 \sim 70$ \\
Pulse current frequency $(\mathrm{Hz})$ & 50 \\
EN ratio & 0.5 \\
Welding speed, v $(\mathrm{cm} / \mathrm{min})$ & $12 \sim 26$ \\
Shielding gas & $100 \% \mathrm{Ar}$ \\
Shielding gas, $\mathrm{q}(\mathrm{l} / \mathrm{min})$ & $8 \sim 15$ \\
Back shielding gas, $1(1 / \mathrm{min})$ & $8 \sim 10$ \\
\hline
\end{tabular}

Table 3. Notation of welding speed

\begin{tabular}{|c|c|}
\hline Notation & Range of rotation angle \\
\hline $\mathrm{v}_{1}$ & $0^{\circ}-90^{\circ}$ \\
\hline $\mathrm{v}_{2}$ & $90^{\circ}-180^{\circ}$ \\
\hline $\mathrm{v}_{3}$ & $180^{\circ}-270^{\circ}$ \\
\hline $\mathrm{v}_{4}$ & $270^{\circ}-360^{\circ}$ \\
\hline
\end{tabular}

Welding process was conducted autogenously for $360^{\circ}$ of circumference and in fixed 
position of pipe. To begin with, the torch started to initiate the arc until the initial penetration was produced. Then by controlling the welding speed, $\mathrm{v}_{1}-\mathrm{v}_{4}$, the experiment without control was conducted. In constant welding current of $60 \mathrm{~A}$, all the training data consisted of the image parameters: width (W), length (L) and area (A), rotation angle $(\theta)$, and welding speed (v) were obtained.

\subsection{Welding Speed Control With Neural Network}

The experiment with control is conducted with the neural network model as control system. The back propagation neural network model is shown in Fig. 8. The input data from experiment without control were used to train the process and outputted the weight of neural network. There were three layers structure consisted of six units in the input layer, eleven units in the hidden layer, and two units in the output layer.

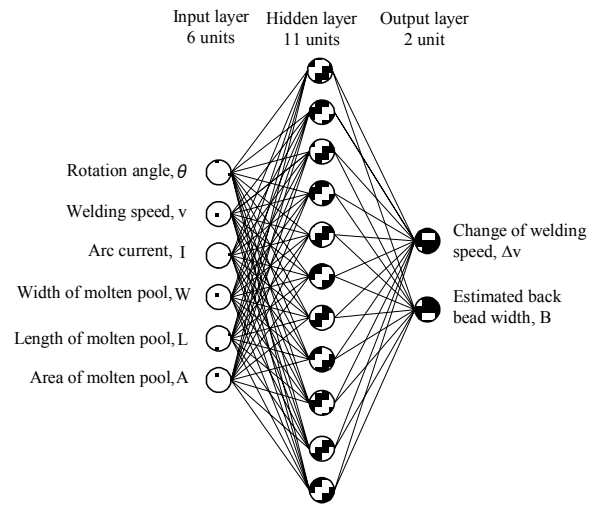

Fig. 8 Neural network model

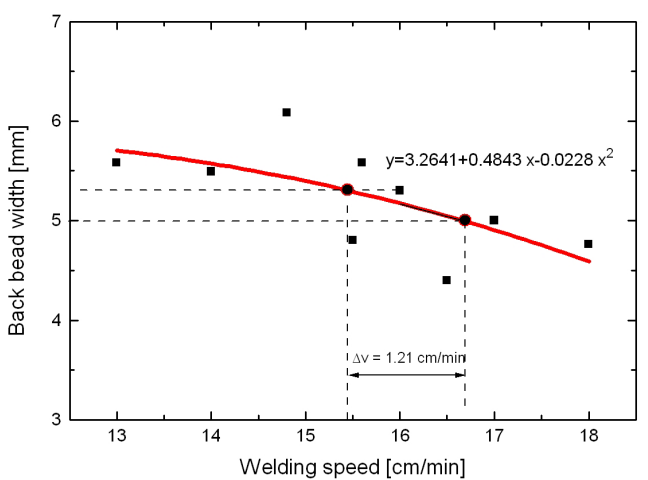

Fig. 9 Second degree polynomial regression of welding speed at $\theta=216^{\circ}$

At the constant welding current of $60 \mathrm{~A}$, the welding speed was controlled by the input data of welding torch rotation angle $(\theta)$, welding speed $(\mathrm{v})$, arc current (I), image width $(\mathrm{W})$, image length (L), and image area (A). From the collected data from the experiment without control, the process to find the change welding speed $(\Delta \mathrm{v})$ was performed for every $4.5^{\circ}$ of rotational increment using linear regression or second degree of polynomial regression of the data. The equation of regression was used to find the change of welding speed to the target of back bead width. Fig. 9 shows the example of second degree of polynomial regression of welding speed at $\theta=216^{\circ}$. If the real back bead width was $5.3 \mathrm{~mm}$ and the polynomial coefficients were: $\mathrm{a}=-0.0228, \mathrm{~b}=0.4843$, and $\mathrm{c}=3.2641$, then we could calculate the real speed at width of $5.3 \mathrm{~mm}$ yielded $15.47 \mathrm{~cm} / \mathrm{min}$. If the target back bead width was $5 \mathrm{~mm}$, then with same procedure above we could find the real speed was $16.68 \mathrm{~cm} / \mathrm{min}$. As the result, we obtained the difference of welding speed was, $\Delta \mathrm{v}=16.68$ $15.47=1.21 \mathrm{~cm} / \mathrm{min}$. In this experiment, the target of back bead width was $5 \pm 1 \mathrm{~mm}$.

The first output of neural network $\Delta \mathrm{v}$ was inputted directly into the motor control to rotate the welding torch. The second output of neural network B was used to estimate the back bead width using neural network. The 387 pairs of data were composed and processed into neural network training. Finally, the result of control welding was measured and analyzed.

\section{Result and discussion}

During the experiment, pipe welding system exactly performed the decided sequence of welding torch movement which shows a very flexible aspect of the system. For experiment without control, detection of molten pool image was conducted for every $4.5^{\circ}$ of rotation angle. The results of experiment without control by monitoring backside image of molten 
pool are shown in Fig. 10.

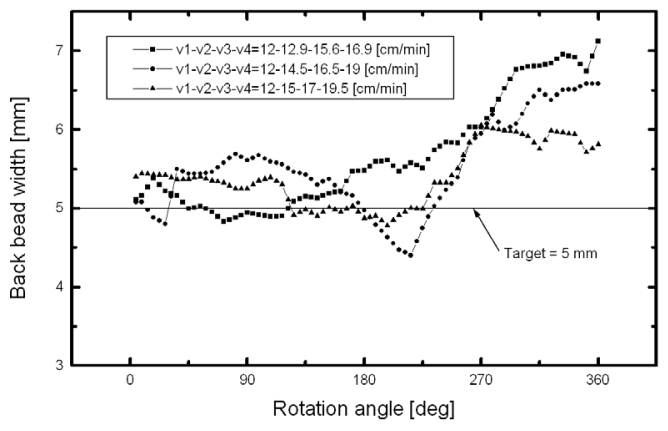

(a) Welding result with different welding speed of $v_{3}-v_{4}$

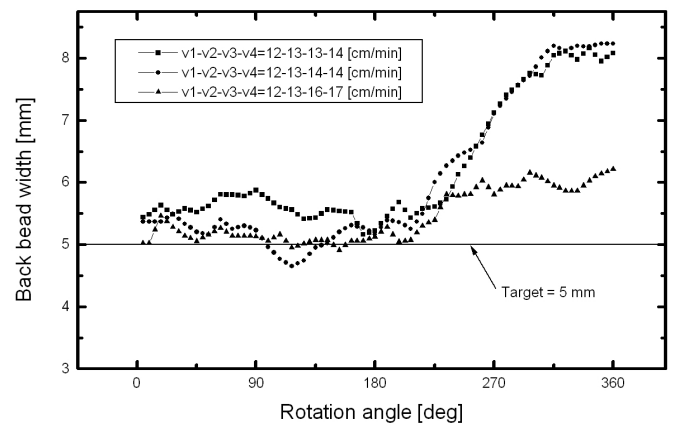

(b) Welding result with different welding speed of $v_{2}-v_{4}$

Fig. 10 Results of experiment without control

In Fig. 10(a), three kind of welding speed with same values of $v_{1}-v_{2}$ and different values of $v_{3}-v_{4}$ were observed. In this experiment, by increasing the values of $v_{3}$ and $v_{4}$ at 16 and $17 \mathrm{~cm} / \mathrm{min}$, respectively, the back bead width could be decreased until $6 \mathrm{~mm}$. In contrary, by inputting $\mathrm{v}_{3}-\mathrm{v}_{4}$ with the value around $13-14 \mathrm{~cm} / \mathrm{min}$ produced the final back bead width of about $8 \mathrm{~mm}$. However, for achieving the target value of back bead width of 5 $\mathrm{mm}$, the welding speed was still not enough. Therefore, it was necessary to observe the last three value of welding speed of $\mathrm{v}_{2}-\mathrm{v}_{4}$.

Figure 10(b) shows the welding result with different welding speed of $v_{2}-v_{4}$. At the beginning of welding process with $\theta=0^{\circ}-180^{\circ}$, all of the different welding speed showed the same values around the target value of back bead width. However, by increasing the welding speed at $v_{3}-v_{4}$, the back bead width showed the different result at the range of $6-$ $7 \mathrm{~mm}$. The smallest value of welding speed of $\mathrm{v}_{4}$ was set at $19.5 \mathrm{~cm} / \mathrm{min}$. From these experiments, it was shown that the value of welding speed of $v_{2}$ was very important. Although by increasing the value of $\mathrm{v}_{2}$ produces almost the same back bead width at $\theta=90^{\circ}$ $-180^{\circ}$, but it influenced the next welding result at $\theta=180^{\circ}-360^{\circ}$.

From the experiment to evaluate the neural network system, the comparison between back bead width obtained from the neural network and measurement is shown in Fig. 11. In this experiment, to produce stable arc condition, the welding speed of $12 \mathrm{~cm} / \mathrm{min}$ at $\theta=0^{\circ}-$ $45^{\circ}$ was kept constant. Figure 11(a) shows the comparison between estimated back bead width using neural network and measured back bead width. In Fig. 11(b) presents the error of back bead width estimation. At $\theta=45^{\circ}-135^{\circ}$ estimated back bead width error was about $-1 \mathrm{~mm}$, and at $\theta=270^{\circ}-360^{\circ}$, error was more than $1 \mathrm{~mm}$. Nevertheless, most of the errors were aligned in the tolerance value of $4-6 \mathrm{~mm}$ and the average error of the estimation was $-0,07 \mathrm{~mm}$. The possible cause of errors could come from the error of measurement of back bead width. Another reason of these errors was the training data for neural network were not sufficient. 


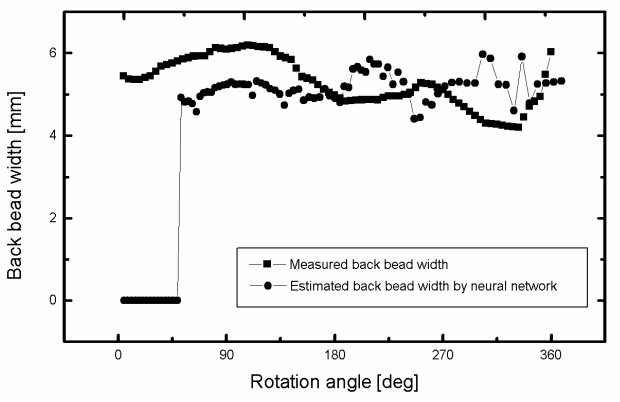

(a) Comparison between estimated and measured back bead width

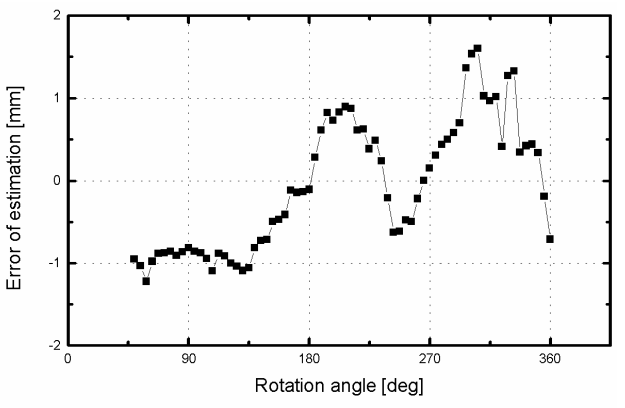

(b) Error of the estimation of back bead width

Fig. 11 Result of estimated back bead width using neural network

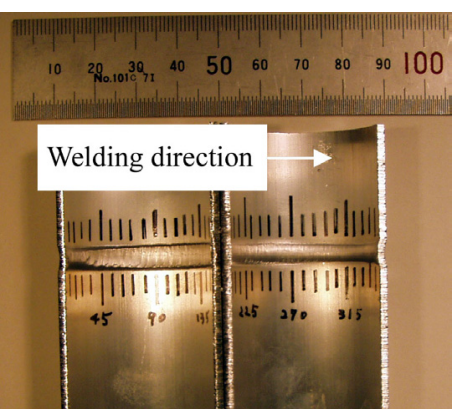

(a) Back bead

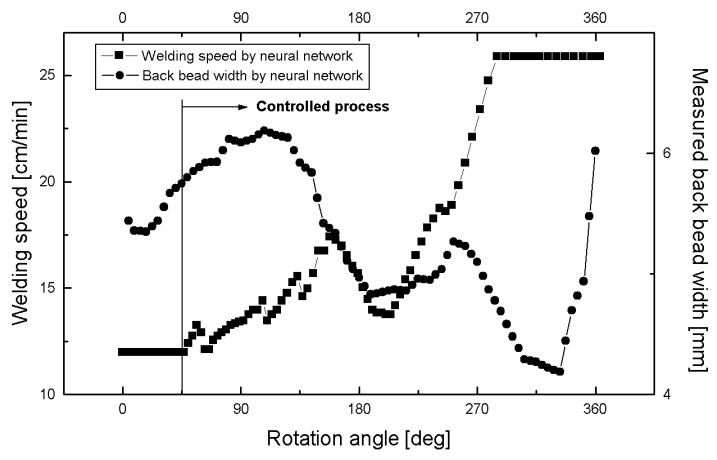

(b) Welding speed and back bead width

Fig.12 Result of experiment using neural network control

The experiment result using neural network is shown in Fig. 12. Figure 12(a) shows sound weld of back bead. The cleaning area in with and without control results were almost same at $10-12 \mathrm{~mm}$ in width. Having this result, the cleaning area was not influence greatly in the control process. The welding speed and measured back bead width is shown in Fig. 12(b). At $\theta=45^{\circ}-135^{\circ}$, the welding speed increased slowly from $12-15 \mathrm{~cm} / \mathrm{min}$ and the error of back bead width increased and exceeded $1 \mathrm{~mm}$. However, by increasing the welding speed until $17.5 \mathrm{~cm} / \mathrm{min}$, the error of back bead width decreased to $0 \mathrm{~mm}$ at $\theta=$ $180^{\circ}$. Then, the welding speed was reduced to $14 \mathrm{~cm} / \mathrm{min}$ at $\theta=180^{\circ}$ and increased again up to $26 \mathrm{~cm} / \mathrm{min}$ to saturated value of welding speed at $\theta=270^{\circ}$. This welding speed has decreased error of back bead width less than $0 \mathrm{~mm}$ and more than $-1 \mathrm{~mm}$. In general, the average error of back bead with using neural network model was $0.27 \mathrm{~mm}$.

This experiment result shows a good agreement with previous experiment without control that the welding speed at $\theta=90^{\circ}-180^{\circ}$ was very important to affect next welding result. Accordingly, by proper control of welding speed, it will produce excellent back bead width. The experiment result shows that the bead was smooth in appearance and there was no crack, porosity, undercut and burn through along the circumference. The back bead width also aligned in the range target of $4-6 \mathrm{~mm}$ in width. In this study, the welding condition was change during the welding proceeded along the circumference of the pipe. However, the suitable welding condition for producing the good result was obtained at welding current, $\mathrm{I}=60 \mathrm{~A}$, pulsed current frequency, $\mathrm{f}=50 \mathrm{~Hz}$, minimum welding speed, $\mathrm{v}_{\min }=12 \mathrm{~cm} / \mathrm{min}$, and maximum welding speed, $\mathrm{v}_{\max }=26 \mathrm{~cm} / \mathrm{min}$. In general, the proposed automatic welding system produced sound weld of aluminum pipe by monitoring backside image of molten pool.

\section{Conclusion}

Main results obtained by the investigation are summarized as follows. 
1) An automatic welding process of aluminum pipe welding system by monitoring backside image of molten pool using vision sensors was constructed.

2) An algorithm to obtain edge detection's range to detect edge of molten pool was proposed. Image processing based on differential value of brightness was proposed to detect edge of molten pool and the validity of the system was confirmed.

3) As a result of welding experiments, the effectiveness of automatic welding system was demonstrated and sound weld was obtained.

\section{References}

[1] Kou, S., Le, Y., Heat flow during the autogeneous GTA welding of pipes, Metallurgical Transactions A, 15A (1984), pp.1165-1171

[2] Lho, T.J., Na, S.J., A study on parameter optimization with numerical heat conduction model for circumferential gas tungsten arc (GTA) welding of thin pipes, Proc. Inst Mechanical Engineers, Part B, 206 (1992), pp.101-111

[3] Na, S.J., Lee, H.J., A study on parameter optimization in the circumferential GTA welding of aluminum pipes using a semi-analytical finite-element method, Journal of Material Processing Technology 57 (1996), pp.95-102

[4] Kondoh, K., Ohji, T., and Ueda, K., Optimum heat input control in arc welding of steel and aluminum pipe, Material Transaction, JIM, vol 39 no. 3 (1998), pp.413-419

[5] Muramatsu, M., Suga, Y., Mori, K., Autonomous Mobile Robot System for Monitoring and Control of Penetration during Fixed Pipes Welding, JSME International Journal Series A, Volume 46, No.3, (2003), pp.391-397

[6] Baskoro, A.S., Suga, Y., Investigation of Welding Penetration Control in TIG Welding of an Aluminum Pipe using Vision Sensing, The 14th Material and Processing 2006 (M\&P 2006), JSME, November 25-25, Chiba, Japan (2006), pp.131-132 